\title{
Evidence for Linkage of a Candidate Chromosome 1 Region to Human Systemic Lupus Erythematosus
}

\author{
Betty P. Tsao, ${ }^{*}$ Rita M. Cantor, ${ }^{\ddagger}$ Kenneth C. Kalunian, ${ }^{\star}$ Chung-Jen Chen, ${ }^{\S}$ Humeira Badsha, ${ }^{*}$ Rattandeep Singh, ${ }^{\star}$ \\ Daniel J. Wallace, ${ }^{\ddagger}$ Rodanthi C. Kitridou, ${ }^{\|}$Shun-le Chen, " Nan Shen, ${ }^{\rrbracket}$ Yeong W. Song, ${ }^{\star \star}$ David A. Isenberg, ${ }^{\ddagger \neq}$ Chia-Li Yu, ${ }^{\$ \S}$ \\ Bevra H. Hahn, ${ }^{\star}$ and Jerome I. Rotter ${ }^{\ddagger}$ \\ *University of California, Los Angeles, Los Angeles, California; ${ }^{\ddagger}$ Cedars-Sinai Research Institute, Los Angeles, California; ${ }^{\S}$ Kaohsiung \\ Medical College, Kaohsiung, Taiwan; "University of Southern California, Los Angeles, California; "Shanghai Second Medical College, \\ Shanghai, People’s Republic of China; **Seoul National University Hospital, Seoul, Korea; ${ }^{*}$ University College of London, United \\ Kingdom; and ${ }^{\S}$ Veterans General Hospital, Taipei, Taiwan
}

\begin{abstract}
Genetic susceptibility confers significant risk for systemic lupus erythematosus (SLE). The MHC region and other polymorphic loci have been associated with SLE. Because more compelling evidence for an involvement of a genetic locus includes linkage, we tested a candidate region homologous to a murine SLE susceptibility region in 52 SLE-affected sibpairs from three ethnic groups. We analyzed seven microsatellite markers from the human chromosome 1q31-q42 region corresponding to the telomeric end of mouse chromosome 1 , the region where specific manifestations of murine lupus, including glomerulonephritis and IgG antichromatin, have been mapped. Comparing the mean allele sharing in affected sibpairs of each of these seven markers to their expected values of 0.50 , only the five markers located at 1q41-q42 showed evidence for linkage $(P=0.0005-0.08)$. Serum levels of IgG antichromatin also showed evidence for linkage to two of these five markers $(P=0.04)$, suggesting that this phenotype is conserved between mice and humans. Compared to the expected random distribution, the trend of increased sharing of haplotypes was observed in affected sibpairs from three ethnic groups $(P<0.01)$. We concluded that this candidate 1q41-q42 region probably contains a susceptibility gene(s) that confers risk for SLE in multiple ethnic groups. (J. Clin. Invest. 1997. 99:725-731.) Key words: human SLE • affected sibpairs • susceptibility • linkage analysis $\bullet$ homology
\end{abstract}

\section{Introduction}

Systemic lupus erythematosus (SLE) $)^{1}$ is an autoimmune rheumatic disease characterized by the tissue disposition of autoan-

Address correspondence to Betty P. Tsao, Ph.D., 32-47 Rehabilitation Center, University of California, Los Angeles, Box 951670, Los Angeles, CA 90095-1670; Phone: 310-825-8906; FAX: 310-206-8606; E-mail: btsao@med1.medsch.ucla.edu

Received for publication 19 September 1996 and accepted in revised form 17 December 1996.

1. Abbreviations used in this paper: dsDNA, double-stranded DNA; GN, glomerulonephritis; IDDM, insulin-dependent diabetes mellitus; SLE, systemic lupus erythematosus.

J. Clin. Invest.

(C) The American Society for Clinical Investigation, Inc.

0021-9738/97/02/0725/07 \$2.00

Volume 99, Number 4, February 1997, 725-731 tibodies and immune complexes leading to tissue injury (1). The serological hallmark of this disease is elevated serum levels of IgG antibodies to nuclear constituents such as doublestranded DNA (dsDNA) and chromatin. Among these autoantibodies, IgG anti-dsDNA antibodies play a major role in the development of lupus glomerulonephritis (GN) (2-3). Mechanisms by which these autoantibodies are induced remain unclear. Chromatin and/or nucleosomes which are released by apoptotic cells in SLE may be autoantigens that induce autoimmune responses, including antibodies to dsDNA (4-6). The actual mechanisms may be best delineated after the susceptibility genes for SLE are described, because it appears that genetic factors exert the greatest influence on autoantibody production and on predisposition to SLE (7).

Studies of populations, segregation of disease in families, and twin concordance rates have consistently demonstrated the importance of genetic influences on SLE (7). The risk for siblings of SLE patients to develop disease is estimated to be 20 times higher than that of the general population (7-9). The genetic basis for SLE is complex, with an unknown but nonMendelian mode of inheritance. Many investigators have reported that certain MHC class II alleles or complement gene deficiencies (homozygous deficiency of $\mathrm{C} 1 \mathrm{q}, \mathrm{C} 2$, and $\mathrm{C} 4$ ) are associated with SLE in most ethnic groups studied $(7,10,11)$. Other alleles at polymorphic genes have also been reported to be associated with SLE, but their contributions are now well defined (reviewed in 7). These polymorphic candidate genes include those that encode mannose-binding protein, Ro/SSA, CR1, IL-6, Ig Gm and $\mathrm{Km}$ allotypes, TcR, TNF $\alpha$, Fc $\gamma R I I A$, and Hsp-70 (12-24). Some of these candidate genes may confer risk to subsets of SLE patients. For example, the Fc $\gamma R I I A$ polymorphism (the gene encoding a $40-\mathrm{kD}$ Fc $\gamma \mathrm{R}$ expressed on human mononuclear phagocytes and neutrophils) has been associated with SLE GN in African Americans but not in Caucasians in one study (22), and in Caucasians in another study (23). A possible genetic linkage of $F c \gamma R I I I A$ with lupus has been reported in a sample of four African-American multiplex families (25). The $F c \gamma R I I A$ and $F c \gamma R I I I A$ genes are located at the chromosome 1q23-q24 region.

Elements complicating the study of disease-causing genes in genetically complex diseases such as human SLE include ethnic diversity, clinical heterogeneity (and presumably genetic heterogeneity), reduced penetrance, and the effect of environment $(26,27)$. In contrast, murine models of spontaneous lupus in inbred strains are less complex. Genetic studies of murine SLE have identified susceptibility loci in several inbred strains which spontaneously develop SLE GN (28). These studies have included genome-wide searches for evidence of linkage using backcrosses or F2 intercrosses of lupus mice such 
as MRL/lpr, NZB/NZW, and NZM/Aeg2410 (29-33). The distal end of mouse chromosome 1 was shown to predispose to specific manifestations of SLE, including GN, IgG antibodies to chromatin, DNA and histone, and splenomegaly $(30,31,33-$ 36). Because important susceptibility genes may be conserved between mice and humans, we have chosen to focus initially on the chromosome 1q21-q42 region corresponding to the murine SLE susceptibility region identified in three independent crosses $(30,31,33)$. Here we report that the tested markers present in the human chromosome 1q41-q42 region show evidence of linkage to human SLE, as well as to the presence of IgG antichromatin autoantibodies.

\section{Methods}

Family enrollment. 43 families with at least two siblings who met the revised 1982 American College of Rheumatology classification criteria for SLE (37) were recruited. These families contained 52 affected sibpairs; 40 families contained 2 affected sibs (e.e., 40 affected sibpairs), 2 contained 3 affected sibs (for a total of 6 affected sibpairs) and one contained 4 affected sibs ( 6 affected sibpairs total). 30 families were from Southern California, 8 from Taiwan, 2 from England, 2 from China, and 1 from Korea. Both parents and unaffected sibs, if available, were included in the study to enable the genetic markers to be maximally informative for identity-by-descent status to be used in the linkage tests. 19 sibpair families had both parent available, 12 had one parent, and the remaining 12 had no available parent for testing. The SLE patients ranged in age from 10 to $75 \mathrm{yr}$, sex distribution was $74 \%$ females and $26 \%$ males. Siblings of SLE patients were classified as unaffected by self-reporting. The youngest unaffected sib in our cohort was $14 \mathrm{yr}$ old. Because of the wide range of age of onset for SLE ( $<1$ to over $60 \mathrm{yr}$ old; 9), no age limit for unaffected sibs can be effectively used to exclude those who may develop SLE at a later time. Each participant donated peripheral blood for serum and DNA. This study was approved by the Human Subject Protection Committee of the University of California, Los Angeles (UCLA).

Clinical studies. Data from medical records for each SLE patient/ proband were reviewed by UCLA rheumatologists and entered into the SLE database. This database was used for confirmation of diagnosis of SLE (requiring at least four of the 11 American College of Rheumatology criteria; 37). DNA and serum were stored for each proband and family member.

Antichromatin IgG antibodies. Histone H1-stripped chromatin (referred to hereafter as chromatin) was prepared from calf thymus as described as Burlingame and Rubin (39). Chromatin (10 $\mu \mathrm{g} / \mathrm{ml} \mathrm{na}-$ tive DNA) was diluted in PBS and applied in 50- $\mu$ l aliquots to Immulon II plates as antigen for $1 \mathrm{~h}$ at room temperature. After washing, these wells were blocked with $100 \mu l$ of $10 \%$ FCS plus $0.05 \%$ Tween 20 in PBS for $1 \mathrm{~h}$. All serum samples were diluted 1:100 in 5\% FCS in PBS. $50 \mu$ l of diluted serum samples were applied to the wells in duplicates. After washing with $0.1 \%$ Tween 20 in PBS, goat anti-human $\mathrm{IgG}$ (Fc-specific) conjugated with alkaline phosphatase was applied. Subsequently, these plates were washed and color reaction was developed $30 \mathrm{~min}$ after the addition of substrate.

Anti-dsDNA IgG antibodies. This ELISA was performed as previously described (39) using serum samples diluted 1:100 in 5\% FCS in PBS. Each plate contained known positive and negative controls in addition to test serum samples. The DNA used was calf thymus dsDNA treated to remove single strand nicks. Because the levels of IgG anti-dsDNA fluctuate with time in SLE patients, a single serum sample from studied subjects may provide false negative results. However, historical information regarding anti-DNA titers extracted from medical records of SLE patients could not be used for quantitative trait analysis because of $(a)$ missing data from some patients, $(b)$ absence of normal ranges from some laboratory reports, and $(c)$ use of multiple methods, none of which is standardized.

Genotyping. DNA was isolated from peripheral blood cells. Microsatellite markers at or near the specific candidate chromosomal region were typed. The primers for these markers were purchased from Research Genetics (Huntsville, AL). Microsatellite genotyping was determined by scoring the size of PCR products. PCR was performed in a 96-well plate using a thermocycler (MJ Research, Inc., Watertown, MA) which was programmed for $95^{\circ} \mathrm{C}$ for $1 \mathrm{~min}, 58^{\circ} \mathrm{C}$ for $30 \mathrm{~s}$, and $72^{\circ} \mathrm{C}$ for 1 min, with 25 cycles. The labeled PCR products were denatured and separated on a $5 \%$ sequencing gel.

The candidate region. Murine susceptibility regions on chromosome 1 , their syntenic human chromosomal regions, and the approximate location of seven tested microsatellite markers are depicted in Fig. 1. These seven markers, located on 1q31-q42 spanning an $\sim 27-\mathrm{cM}$ region, were used to genotype the SLE multiplex families. Both the genetic distance and the cytogenetic assignment were based on the composite map, which integrates physical, radiation hybrid, genetic linkage, and cytogenetic assignment (40). The sex-averaged distance, chromosomal location and heterozygosity index of each marker are shown in Table I.

Analytic strategy including statistical linkage analyses. In order to assess cosegregation of the lupus phenotype with markers in the region of interest on chromosome 1 , we employed several nonparametric linkage tests, i.e., tests for which the model of inheritance of the disease does not have to be hypothesized (41). Each of the seven
A. Murine Susceptibility Regions

\begin{tabular}{|c|c|c|c|c|c|}
\hline Strain & Locus & ״markers: & D1Mit101 & D1Mit111 & D1Mit155 \\
\hline NZW & Sle1 & & & & \\
\hline & & $\mathrm{cM}: 0$ & $\begin{array}{c}73 \\
\text { D1Nds1 }\end{array}$ & $\begin{array}{c}92 \\
\text { D1Mit111 }\end{array}$ & $\begin{array}{c}112 \\
\text { D1Mit155 }\end{array}$ \\
\hline NZB & Nba2 & & & & \\
\hline & & 0 & $\begin{array}{c}67 \\
\mathrm{D} 1 \mathrm{Nds} 1\end{array}$ & $\begin{array}{c}92 \\
\text { D1Mit36 }\end{array}$ & 112 \\
\hline NZB & $L b w-7$ & & & & \\
\hline
\end{tabular}

B. Human Homologous Region

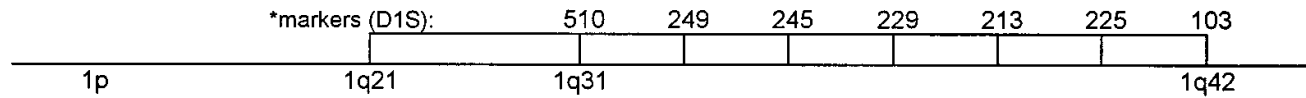

Figure 1. Murine susceptibility regions $(A)$, their human homologous region $(B)$, and relative positions of tested markers. (A) Murine SLE susceptibility regions are located within the distal end of mouse chromosome 1 marked by $D 1 N d s 1$ and D1Mit155, which correspond to the human chromosome $1 \mathrm{q} 21-\mathrm{q} 42$ region as shown in $(B)$. The seven markers tested in this study are located within chromosome $1 \mathrm{q} 31-\mathrm{q} 42$ region. *Approximate marker position (not to scale) was obtained from the mouse genome database at http://www.informatics.JAX.org/. The mouse/human homology was obtained at http:// www3.ncbl.nlm.gov/Homology/. The human chromosome 1 composite map was obtained at http://cedar/genetics/soton.ac.uk/public-html/. 
Table I. Markers Tested for Linkage to SLE and SLE-related Traits

\begin{tabular}{|c|c|c|c|c|c|c|}
\hline $\begin{array}{c}\text { Marker } \\
\text { No. }\end{array}$ & $\begin{array}{c}\text { Marker } \\
\text { locus }\end{array}$ & 5' Primer & 3' Primer & $\begin{array}{l}\text { Chromosome } \\
\text { locus* }\end{array}$ & $\begin{array}{c}\text { Genetic } \\
\text { distance }(\mathrm{cM})^{\ddagger}\end{array}$ & HET $^{\S}$ \\
\hline 1 & DIS510 & AACCCGAGGTGTCTGTGG & AGGGAACAAAATGTGACCTGTAT & $1 \mathrm{q} 31$ & 222 & 0.79 \\
\hline 2 & DIS249 & TGGCATGTCTTTGAAGGAAT & TGGTTGTAGATGAGACTGGC & $1 \mathrm{q} 32$ & 226 & 0.88 \\
\hline 3 & DIS245 & GACCCCTTTACCTGAGGC & CGCTTTGATAGATTTAGCACTG & $1 \mathrm{q} 41$ & 234 & 0.83 \\
\hline 4 & DIS229 & GCTTGTTTCCATTTATGGTG & ACTCTAGTTGTGTGTGAATGTATG & $1 \mathrm{q} 42$ & 242 & 0.78 \\
\hline 5 & DIS213 & CATTATCCAAGGTCAGGAGG & AGCTGTTAATCCAATCTATGATGTG & $1 \mathrm{q} 42$ & 247 & 0.87 \\
\hline 6 & DIS225 & GCCTGGGTGACAAAGCA & TGGCCTGAATAGACCATAAAAA & $1 \mathrm{q} 42$ & 248 & 0.80 \\
\hline 7 & DIS103 & ACGAACATTCTACAAGTTAC & TTTCAGAGAAACTGACCTGT & $1 \mathrm{q} 42$ & 249 & 0.80 \\
\hline
\end{tabular}

*¥The assignment of chromosome locus and sex-averaged genetic distance is from the composite map (40). ${ }^{\S}$ Heterozygosity index.

markers in the region of mouse-human homology was tested for linkage separately, first using only data from pairs of affected siblings, then using data from all sibling pairs in the sample. Two different linkage tests were used with each sample. The advantage of an analysis that uses only affected sibling pairs is that each person in the analysis is assumed to have the disease gene of interest and other unaffected individuals who may have the gene but have not expressed it do not confound the results. In addition to these single marker analyses, we also combined the markers at the most promising region into haplotypes to maximize the information available for linkage. Given that these analyses test a specific candidate region for linkage, we selected $P<0.05$ as our criterion to conduct subsequent analyses. Linkage at this level of significance was followed with genotyping and testing of several flanking markers to investigate the region further.

To assess linkage with the sample of clinically concordant, affected sibling pairs, we calculated the mean allele sharing identicalby-descent at the loci of interest and tested each for a significant difference from the expected value of random marker sharing, 0.5, using the SIBPAL subprogram (42) of the S.A.G.E. package (43). The test statistic follows a binomial distribution. A significant increase in allele sharing (over 0.5), is taken as evidence for linkage (44-47).

We conducted the same analyses including two additional groups of sibpairs; one in which both sibs are unaffected (clinically concordant unaffected sibpairs), and another in which one sib is affected and the other is not (clinically discordant sibpairs). At linked markers, both concordant affected and clinically concordant unaffected sibpairs are expected to demonstrate an increased sharing of marker alleles identical-by-decent, while clinically discordant pairs should exhibit a decreased sharing $(45,46)$. Both clinically concordant unaffected and clinically discordant sibpairs should show weaker evidence for linkage than affected sibpairs, because some unaffected siblings may carry the disease gene and yet not express it due to the lack of time or of other genetic and environmental factors which contribute to the development of disease.

With a second linkage method, we combined data from all three groups of sibpairs using the SIBPAL subprogram (42) of the S.A.G.E. package (43) to regress the trait differences (disease status or levels of autoantibody) in sibpairs against the proportion of marker alleles that they share (48). A significantly negative regression line, representing the phenomenon that those who are phenotypically alike tend to share more alleles and those who are discordant tend to exhibit less allele sharing, is taken as evidence for linkage. If there is no linkage, this analysis yields a horizontal line with the regression coefficient not significantly different from zero. This is assessed by dividing the regression coefficient by its standard error and comparing it to a $t$ value for the appropriate degrees of freedom.

We then constructed haplotypes of the three markers in the most promising region identified by the prior analyses and tested them simultaneously for linkage. First, we examined the observed distribution in haplotype sharing for the affected sibpairs and compared it with what is expected by chance alone using a chi-square test of goodness-of-fit test (49). A significant difference from the theoretical distribution, with the number of pairs sharing two or one alleles exceeding what is expected, is taken as evidence for linkage. Often using haplotype information will improve the significance level of a linkage result by increasing the informativeness of the markers (50). This approach is, however, vulnerable to the loss of information due to crossover events within the region of interest. We then tested the haplotype for linkage with both the mean allele sharing test and the regression test.

\section{Results}

We first performed separate linkage analyses for each of seven markers located on human chromosome 1q31-q42 region using the SIBPAL program (42) of the S.A.G.E. package (43). Except for markers D1S510 and D1S249 $(P>0.1)$, as shown in Table II, each of the remaining five markers provided evidence for linkage to the disease, with increased mean allele

Table II. Affected Sibpair Linkage Analysis of SLE and Chromosome 1 Markers or Haplotypes

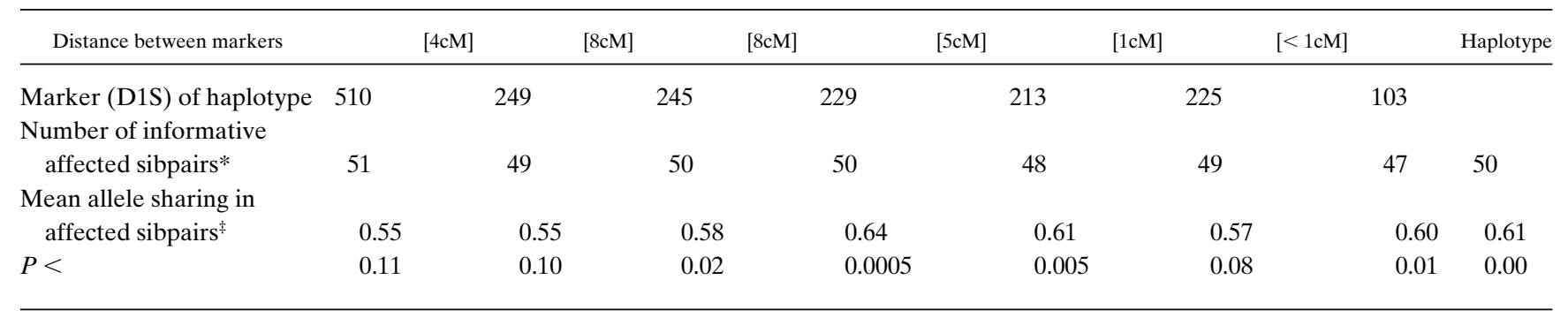

*The number of informative sibpairs for a given marker is reduced in case of homozygosity or allele sharing in parents. ${ }^{\ddagger}$ All are greater than 0.5 , the expected value for no linkage. Numbers of alleles observed range from 8 to 17 for these seven markers. 


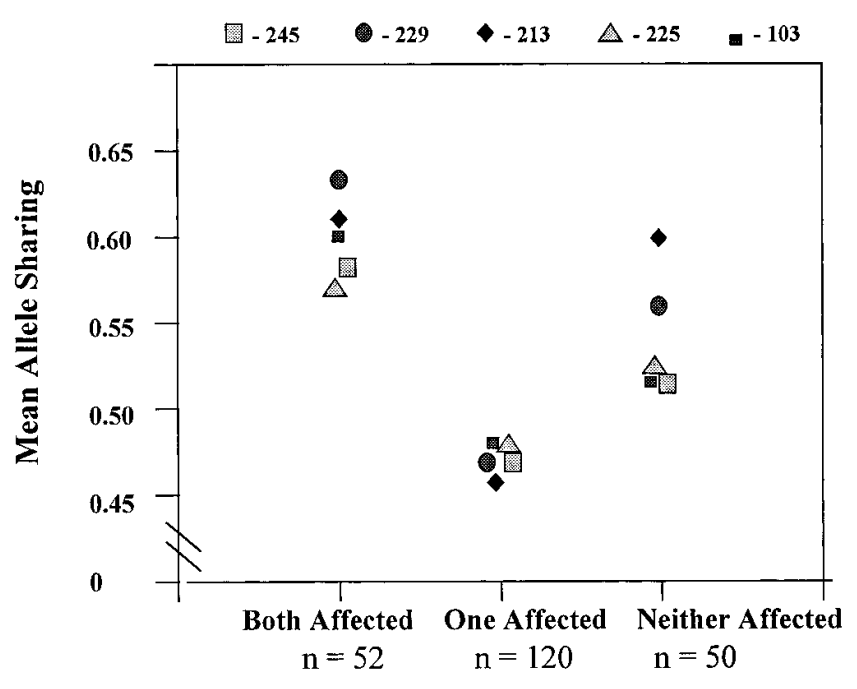

Figure 2. Mean allele sharing in SLE sibpairs for five chromosome 1 markers. Each data point represents the result for a specific marker sharing of the five separate markers. This analysis includes 52 affected sibpairs, 120 clinically discordant pairs (where one is affected and one is not), and 50 nonaffected pairs from the 43 studied SLE multiplex families.

sharing ( 0.57 to $0.64, P=0.0005$ to 0.08 ). The variation in levels of significance may be attributed to the informativeness of each marker and the distance of the marker from the disease gene. To examine the effect of these markers simultaneously, we chose the three contiguous markers, D1S229, D1S213, and D1S225 (within a 7-cM region), containing the strongest linkage results and combined them into groups of linked markers on one chromosome, termed haplotypes, thus allowing us to trace their inheritance as a group. Similar to the $H L A$ region, haplotypes are often more informative than individual markers. As shown in Table II, the allele sharing of this haplotype yielded similar evidence for linkage (mean allele sharing $=$ 0.61 and $P=0.007)$. In contrast to the range of mean marker sharing in 52 affected sibpairs ( 0.57 to 0.64 , Table II), 120 discordant pairs (where one is affected and one is not) yielded estimates of reduced marker sharing ranging between .46 and .49 for the five markers (Fig. 2). Sharing in the 50 pairs where neither was affected at the time of analysis resulted in estimates of between 0.50 and 0.60 depending on the specific marker (Fig. 2 ). This pattern of excess sharing at each of the loci in the candidate region for both types of concordant pairs as well as reduced sharing in clinically discordant pairs, provides further evidence for linkage. The smaller mean allele sharing for unaffected sibpairs compared to that for affected pairs $(0.50-0.60$ vs. 0.57-0.64) is consistent with the possibility that among the unaffected sibs, some may carry the SLE gene and will develop SLE over time, i.e., that they are actually genetically discordant.

We also conducted linear regression analyses to assess whether the pattern of differences in SLE in sibpairs varies in relation to the degree of allele sharing at the marker locus. Different disease status (one affected and one unaffected) in the sibpair should result in decreased allele sharing while the same disease status (either both affected or both unaffected) should result in increased sharing. When these differences in
Table III. Regression of Marker Sharing Identical-by-Descent and Differences in SLE Status within Pairs*

\begin{tabular}{lll}
\hline \multicolumn{1}{c}{ (D1S) } & $t$ values $^{\ddagger}$ & $P$ value \\
\hline 245 & -1.84 & 0.04 \\
229 & -3.41 & 0.0005 \\
213 & -1.87 & 0.03 \\
225 & -3.49 & 0.0004 \\
103 & -1.51 & 0.07 \\
Haplotype & -1.58 & 0.06 \\
\hline
\end{tabular}

*Regression analyses were based on 50 unaffected sibpairs, 120 sibpairs discordant for disease, and 52 sibpairs where both are affected. *Estimated regression coefficient divided by its standard error.

disease status are regressed against the degree of allele sharing for all sibpairs, a negative slope is indicative of linkage. As shown in Table III, the tested five markers as well as the haplotype showed negative slopes of the regression lines $(P=$ 0.0004 to 0.07 ), thus further supporting the evidence for linkage in this region.

We compared our observed allele sharing in the affected pairs with a theoretical distribution for no linkage in that region (25\% sharing 0 alleles, $50 \%$ sharing 1 , and $25 \%$ sharing $2)$. The haplotype distribution defined by markers $D 1 S 229$, $D 1 S 213$, and $D 1 S 225$ in 50 affected sibpairs yielded a $P$ value less than 0.01 using a $\chi^{2}$ tests for goodness-of-fit against the expected distribution (Table IV). Because of crossover events within this region, two affected sibpairs were excluded from this analysis. We included the distribution delineated by ethnic groups as well; the trend of increased sharing of haplotypes was observed in affected sibpairs from these three ethnic groups individually and as a whole (Table IV). Using haplotype sharing information from the entire sample, we estimate the sibling recurrence risk ratio which may be attributable to the potential susceptibility locus in this region to be 4.17 (51).

Because this murine susceptibility region on mouse chromosome 1 was linked to the presence of $\mathrm{IgG}$ antichromatin antibodies in the mouse $(30,34,35)$, all family members were assayed for serum $\operatorname{IgG}$ antibodies to chromatin. To assess whether linkage of antichromatin $\mathrm{IgG}$ is conserved between mice and humans, we tested serum levels of this autoantibody for linkage to this candidate region. Because levels of some autoantibodies fluctuate over time, this analysis at one time may underestimate the tested autoantibody as a quantitative trait. Nevertheless, even with this possible confounding, as shown in Table V, antichromatin IgG antibodies showed tentative

Table IV. Chromosome 1 Haplotype Sharing in Affected Sibpairs by Ethnic Group

\begin{tabular}{lccr}
\hline & \multicolumn{3}{c}{ IBD Sharing } \\
\cline { 2 - 4 } \multicolumn{1}{c}{ Ethnicity } & 0 & 1 & 2 \\
\hline Caucasian & 3 & 13 & 9 \\
Asian & 0 & 13 & 1 \\
African American & 0 & 8 & 3 \\
Total* & 3 & 34 & 13 \\
& & &
\end{tabular}

${ }^{*} \chi^{2}=10.48, P<0.01$ 
Table V. Regression of Marker Sharing in Sibpairs and Squared Differences of Autoantibody Levels

\begin{tabular}{lcc}
\hline & \multicolumn{2}{c}{$P$ values } \\
\cline { 2 - 3 } \multicolumn{1}{c}{ D1S $)$} & Antichromatin & Anti-DNA \\
\hline 245 & 0.12 & 0.72 \\
229 & 0.04 & 0.89 \\
213 & 0.04 & 0.85 \\
225 & 0.07 & 0.87 \\
103 & 0.07 & 0.91 \\
Haplotype & 0.06 & 0.80 \\
& & \\
\hline
\end{tabular}

evidence for linkage ( $P=0.04-0.12$, effective degrees of freedom $=70$ for these five markers, and $P=0.06$ for the haplotypes). Because $\operatorname{IgG}$ anti-dsDNA antibodies contribute to SLE GN, we assayed serum samples from all family members for $\operatorname{IgG}$ anti-dsDNA. Using the same diluted serum samples, no evidence of linkage was detected for IgG anti-DNA at any of the five markers, with $P$ values ranging from .72 to .91 . The tentative linkage result of $\mathrm{IgG}$ antichromatin to this region supports our mouse to human candidate region approach because this chromosome 1q region is syntenic to the murine susceptibility region containing the Sle1, $\mathrm{Lbw}-7$, and $\mathrm{Nba2}$ loci, which are linked to the production of $\mathrm{IgG}$ antichromatin (30, 34-36). The lack of linkage of IgG anti-dsDNA to this test region is inconsistent with the recent finding that the Nba2 locus is linked to production of autoantibodies to several nuclear antigens including dsDNA (35), but consistent with the previous report of murine linkage analyses that different chromosomal loci correlate with IgG anti-dsDNA (33).

\section{Discussion}

This study has identified a $15 \mathrm{cM}$ region on chromosome $1 \mathrm{q} 41$ $\mathrm{q} 42$ that is linked to human SLE. Previously, the $M H C$ region and several polymorphic gene loci have been related to human SLE by association studies $(7,10,12-24)$, which may yield significant statistical results for reasons other than physical proximity to an SLE gene. We chose to test for linkage a candidate human chromosomal region syntenic to a murine susceptibility region. This murine susceptibility locus (mapped to a 67-112 cM region of chromosome 1 of NZB or NZW genetic origin) was identified repeatedly by linkage analyses of three separate crosses using two inbred strains of lupus-prone mice- $(\mathrm{NZB} \times$ NZW) F1 and NZM/Aeg2410 mice (30, 31, 35, 36). When choosing this region for analysis, we hypothesized that $(a) \mathrm{im}$ portant susceptibility genes may be conserved from mice to humans, and $(b)$ if susceptibility loci are conserved across species, they are likely to be conserved across some racial groups. The first hypothesis is supported by $(a)$ the increased identityby-descent sharing of each separately tested marker within chromosomal region 1q41-q42 (Table II), (b) the significant regression analyses relating marker sharing and disease status in all sibpairs $(P=0.0004-0.07$ for each tested marker in $1 \mathrm{q} 41-$ $\mathrm{q} 42$ ), and (c) the increased identical-by-descent sharing of haplotypes of linked markers (Table IV). Our haplotype analysis (Table IV) showing no obvious differences in sharing among the three racial groups is consistent with our second hypothesis of no racial differences in linkage in this region, although larger sample sizes may reveal differences we cannot detect herein. Thirdly, we further hypothesized that if a specific locus is conserved across species, then the phenotypic expression of that locus could be conserved as well. The tentative linkage of IgG antichromatin to markers of this region is supportive evidence that the phenotypic expression of the locus may be conserved between mice and humans.

Among these seven markers tested, D1S229 appears to be the most promising marker linked to both the disease and to the quantitative trait of $\operatorname{IgG}$ antichromatin antibodies. This might be attributed to the informativeness of this marker and/ or the distance of this marker from a lupus putative susceptibility gene. Because the heterogeneity index of D1S229 is similar if not lower than the other tested markers, it is tempting to speculate that a disease causing gene may be nearest to D1S229 among the markers we have tested. A previous linkage report in human SLE observed an optimal lod score of 2.38 of a marker at $1 \mathrm{q} 23$ in a small sample of four AfricanAmerican families (25).

Our observation of a conserved susceptibility region between mouse and human SLE is not a common finding in autoimmune diseases. For example, linkage analyses of human type I insulin-dependent diabetes mellitus (IDDM) sibpairs and diabetes in the NOD mouse showed that most susceptibility loci did not correlate well with two exceptions: (a) IDDM7 maps to the syntenic region of Idd5, and (b) IDDM1/Idd1 are linked to the MHC region in both species $(8,52,53)$. This lack of correlation between mouse and human for most diabetogenic loci may result from the fact that the NOD mice is the only mouse model for spontaneous IDDM, whereas there are several inbred strains of lupus-prone mice. Our candidate chromosomal region is syntenic to overlaps of murine susceptibility loci derived from more than one genetic origin. If susceptibility genes are conserved across different mouse loci in several strains, they are more likely to be conserved across species. This may account for the observed linkage to the disease and to the $\mathrm{IgG}$ antichromatin phenotype which appears to be conserved between mouse and human as well. Recent success of mapping a putative susceptibility locus for multiple sclerosis in the 5p14-p12 region, which is syntenic to the murine locus Eae2, further supports the utility of this mouse to human approach (54).

Within the candidate chromosomal region 1q21-q42, Fc $\gamma$ RIIa alleles have been associated with SLE GN in African-Americans but not in Afro-Caribbean or Chinese $(22,55)$. The role of $F c \gamma R I I a)$ alleles in Caucasian SLE patients is controversial; an association with SLE GN has been found in the Dutch (23) but not in the American or British Caucasian cohorts $(22,55)$. The distance $(>60 \mathrm{cM})$ between the $1 \mathrm{q} 41-\mathrm{q} 42$ region and the Fc $\gamma R$ RII gene (1q23) makes it unlikely that this gene accounts for our observed linkage. The $C R 1$ gene (complement receptor one, previously $\mathrm{C} 3 \mathrm{~b} / \mathrm{C} 4 \mathrm{~b}$ receptor) maps to chromosome 1q32. A polymorphism for low expression of CR1 has been suggested to be a risk factor for SLE (17), although later studies suggested low expression was acquired (56). The increased marker sharing at the $1 \mathrm{q} 41-\mathrm{q} 42$ region but not at the 1q31-q32 region makes the $C R 1$ gene unlikely to account for our results. Therefore, this chromosome $1 \mathrm{q} 41-\mathrm{q} 42$ region may contain a currently unidentified disease-causing gene or genes. Our mapped interval currently spans $15 \mathrm{cM}$ and may contain up to 500 genes. Several genes (TGFB2, HLX1, and ADPRT) located within this region can encode proteins which may play a 
role in development of SLE (57-59). TGFB2 (transforming growth factor beta-2) can suppress IL-2 dependent $\mathrm{T}$ cell growth (60) and administration of a TGF $\beta$ cDNA expression vector to $\mathrm{MRL} / \mathrm{lpr}$ mice decreases serum IgG antichromatin and delays the onset of SLE (61). HLX1 (homeo box 1) is expressed in hematopoietic progenitors and activated lymphocytes and may regulate development of CD4+ T cells (62). $A D P R T$ (ADP-ribosyltransferase) is induced by DNA damage and plays a role in cellular repair (63). The report that SLE patients and their family members had decreased poly(ADPribose) metabolism makes $A D P R T$ a possible candidate (64). Further analyses of this candidate region (1q41-q42) are in progress and should lead to eventual identification of a specific susceptibility gene or genes for human SLE.

In summary, the data presented herein provide support for the hypothesis that a genetic region homologous to a portion of chromosome 1 in the mouse provides genetic susceptibility to SLE in species as widely divergent as man and mouse. This locus appears to predispose to SLE in all ethnic groups examined.

\section{Acknowledgments}

The authors thank L. Ozaki, S. Pressman, C. McElree, and H. Vora for their expert technical help, Dr. A.J. Lusis at UCLA for advice, and Dr. R.R. Singh for facilitating clinical evaluation of patients.

This study was supported in part by the National Institutes of Health grants R01-AR-33962 and R55-AR-49814, and the CedarsSinai Board of Governors' Chair in Medical Genetics. Work was performed in the Dreyfuss Laboratory for Lupus Research at UCLA, at the Bertram A. Maltz M.D. Laboratory for Molecular Rheumatology, UCLA, and at the Steven Spielberg Pediatric Research Center of the Burns and Allen Cedars-Sinai Research Institute in Los Angeles, CA. The results of sibpair linkage analyses were obtained by using program package S.A.G.E., which is supported by US Public Health Service resource grant 1 P41 RR03655 from the Division of Research Resources.

\section{References}

1. Kotzin, B.L. 1996. Systemic lupus erythematosus. Cell. 85:303-306

2. Hahn, B.H., and B.P. Tsao. 1993. Antibodies to DNA. In Dubois' Lupus Erythematosus. 4th ed. D.J. Wallace and B.H. Hahn, editors. Lea and Febiger, Philadelphia. 195-201.

3. Ohnishi, K., F.M. Ebling, B. Mitchell, R.F. Singh, B.H. Hahn, and B.P. Tsao. 1994. Comparison of pathogenic and nonpathogenic murine antibodies to DNA: Antigen binding and structural characteristics. Int. Immunol. 6:817-830.

4. Burlingame, R.W., M.L. Boey, G. Starkebaum, and R.L. Rubin. 1994. The central role of chromatin in autoimmune responses to histones and DNA is systemic lupus erythematosus. J. Clin. Invest. 94:184-192.

5. Mohan, C., S. Adams, V. Stanik, and S.K. Datta. 1993. Nucleosome: a major immunogen for pathogenic autoantibody-inducing T cells of lupus. $J$. Exp. Med. 177:1367-1381.

6. Bell, D.A., B. Morrison, and P. VandenBygaart. 1990. Immunogenic DNA-related factors. Nucleosomes spontaneously released from normal murine lymphoid cells stimulate proliferation and immunoglobulin synthesis of normal mouse lymphocytes. J. Clin. Invest. 85:1487-1496.

7. Arnett, F.C., Jr. 1993. The genetic basis of lupus erythematosus. In Dubois' Lupus Erythematosus. 4th ed. D.J. Wallace and B.H. Hahn, editors. Lea and Febiger, Philadelphia. 13-36.

8. Vyse, T.J., and J.A. Todd. 1996. Genetic analysis of autoimmune disease. Cell. 85:311-318.

9. Hochberg, M.C. 1993. The epidemiology of systemic lupus erythematosus. In Dubois' Lupus Erythematosus. 4th ed. D.J. Wallace and B.H. Hahn, editors. Lea and Febiger, Philadelphia. 49-76.

10. Schur, P.H. 1993. Complement and systemic lupus erythematosus. In Dubois, Lupus Erythematosus. 4th ed. D.J. Wallace and B.H. Hahn, editors. Lea and Febiger, Philadelphia. 120-127.

11. Bowness, P., K.A. Davies, P.J. Norsworthy, P. Athanassiou, J. TaylorWiedeman, L.K. Borysiewicz, P.A. Meyer, and M.J. Walport. 1994. Hereditary
C1q deficiency and systemic lupus erythematosus. Q. J. Med. 87:455-464.

12. Davis, E.J., N. Snowden, M.C. Hillarby, D. Carthy, D.M. Grennan, W. Thomson, and W.E. Ollier. 1995. Mannose-binding protein gene polymorphism in systemic lupus erythematosus. Arthritis Rheum. 38:110-114.

13. Tsugu, H., R. Horowitz, N. Gibson, and M.B. Frank. 1994. The location of a disease-associated polymorphism and genomic structure of the human 52kDa Ro/SSA locus (SSA1). Genomics. 24:541-548.

14. Schur, P.H., J.P. Pandey, and J.A. Fedrick. 1985. Gm allotypes in white patients with SLE. Arthritis Rheum. 28:828-830.

15. Fedrick, J.A., J.P. Pandey, Z. Chen, H.H. Fudenberg, S.K. Ainsworth, and R.L. Dobson. 1985. Gm allotypes in blacks in SLE. Arthritis Rheum. 28: 828-830.

16. Hoffman, R.W., G.C. Sharp, W.S. Irvin, S.K. Anderson, J.E. Hewett, and J.P. Pandey. 1991. Association of immunoglobulin $\mathrm{Km}$ and $\mathrm{Gm}$ allotypes with specific antinuclear antibodies and disease susceptibility among connective tissue disease patients. Arthritis Rheum. 34:453-458.

17. Cornillet, P., P. Gredy, J.L. Pennaforte, O. Meyer, M.D. Kazatchkine, and J.H. Cohen. 1992. Increased frequency of the long (S) allotype of CR1 (the $\mathrm{C} 3 \mathrm{~b} / \mathrm{C} 4 \mathrm{~b}$ receptor, CD35) in patients with systemic lupus erythematosus. Clin. Exp. Immunol. 89:22-25.

18. Linker-Israeli, M., L. Li, D.J. Wallace, J. Prehn, and J.R. Klinenberg. 1997. A greater variability in the $3^{\prime}$ flanking region of the IL-6 gene in patients with systemic lupus erythematosus. Autoimmunity. In press.

19. Jacob, D.O., Z. Fronek, G.D. Lewis, M. Koo, J.A. Hansen, and H.O. McDevitt. 1990. Heritable major histocompatibility complex class II-associated differences in production of tumor necrosis factor $\alpha$ : relevance to genetic predisposition to SLE. Proc. Natl. Acad. Sci. USA. 87:1233-1237.

20. Bettinotti, M.P., K. Hartung, H. Deicher, G. Messer, E. Keller, E.H. Weiss, and E.D. Albert. 1993. Polymorphism of the tumor necrosis factor $\beta$ gene in SLE: TNFB-MHC haplotypes. Immunogenetics. 37:449-454.

21. Tebib, J.G., J. Alcocer-Verela, D. Alarcon-Segovia, and P.H. Schur. 1990. Association between a T cell receptor restriction fragment length polymorphism and systemic lupus erythematosus. J. Clin. Invest. 86:1961-1967.

22. Salmon, J.E., S. Millard, and L. Schachter. 1996. FcyRIIA alleles are heritable risk factors for lupus nephritis in African-Americans. J. Clin. Invest. 97:1348-1354.

23. Duits, A.J., H. Bootsma, R.H.W.M. Derksen, P.E. Spronk, L. Kater, C.G.M. Kallenberg, P.J.A. Capel, N.A.C. Westerdaal, G.T.H. Spierenburg, F.H.J. Gmelig-Meyling, et al. 1995. Skewed distribution of IgG Fc receptor IIa (CD32) polymorphism is associated with renal disease in systemic lupus erythematosus patients. Arthritis Rheum. 39:1832-1836.

24. Jarjour, W., A.M. Reed, J. Gauthier, S. Hunt, III, and J.B. Winfield. 1996. The 8.5-kb Pst1 allele of the stress protein gene, Hsp70-2: an independent risk factor for systemic lupus erythematosus in African Americans? Hum. Immunol. 45:59-63.

25. Harley, J.B., P. Sheldon, B. Neas, S. Murphy, D.J. Wallace, R.H Scofield, T.S. Shaver, and K.L. Moser. 1994. Systemic lupus erythematosus: Considerations for a genetic approach. J. Invest. Dermatol. 103:144S-149S.

26. Lander, E.S., and N.J. Schork. 1994. Genetic dissection of complex traits. Science (Wash. DC). 265:2037-2048.

27. King, R.A., J.I. Rotter, and A.G. Motulsky, editors. 1992. The Genetic Basis of Common Diseases. Oxford University Press, New York.

28. Theofilopoulos, A.N. 1995. The basis of autoimmunity: Part II. Genetic predisposition. Immunol. Today. 15:150-158.

29. Watson, M.L., J.K. Rao, G.S. Gilkeson, P. Ruiz, E.M. Eicher, D.S. Pisetsky, A. Matsuzawa, J.M. Rochelle, and M.G. Seldin. 1992. Genetic analysis of MRL-lpr mice: Relationship of the Fas apoptosis gene to disease manifestations and renal disease-modifying loci. J. Exp. Med. 176:1645-1656.

30. Kono, D.H., R.W. Burlingame, D. Owens, A. Kuramochi, R.S. Banderas, D. Balomenos, and A.N. Theofilopoulos. 1994. Lupus susceptibility loci in New Zealand mice. Proc. Natl. Acad. Sci. USA. 91:10168-10172.

31. Drake, C.G., S.J. Rozzo, H.F. Hirschfeld, N.P. Smarnworawong, E. Palmer, and B.L. Kotzin. 1995. Analysis of the New Zealand Black contribution to lupus-like renal disease: multiple genes that operate in a threshold manner. $J$. Immunol. 154:2441-2447.

32. Drake, C.G., S.K. Babcock, E. Palmer, and B.L. Kotzin. 1994. Genetic analysis of the NZB contribution to lupus-like autoimmune disease in (NZB $\times$ NZW)F1 mice. Proc. Natl. Acad. Sci. USA. 91:4062-4066.

33. Morel, L., U.H. Rudofsky, J.A. Longmate, J. Schiffenbauer, and E.K. Wakeland. 1994. Polygenic control of susceptibility to murine SLE. Immunity. 1:219-229.

34. Mohan, C., E. Alas, L. Morel, P. Yang, and E.K. Wakeland. 1996. Genetic dissection of SLE pathogenesis: Sle1 on murine chromosome 1 leads to loss of tolerance to H2A/H2B/DNA subnucleosomes. Arthritis Rheum. 39:S216 (Abstr).

35. Vyse, T.J., C.G. Drake, S. Izui, and B.L. Kotzin. 1996. Mapping an NZB locus on chromosome 1 linked with lupus nephritis, autoantibody production and total IgG3 levels. Arthritis Rheum. 39:S216 (Abstr)

36. Morel, L., Y. Yu, K.R. Blenman, R.A. Caldwell, and E.K. Wakeland. 1996. Production of congenic mouse strains carrying genomic intervals containing SLE-susceptibility genes derived from the SLE-prone NZM2410 strain. Mamm. Genome. 7:335-339. 
37. Tan, E.M., A.S. Cohen, J.F. Fries, A.T. Masi, D.J. McShane, N.F. Rothfield, J.G. Schaller, N. Talal, and R.J. Winchester. 1982. Special article: The 1982 revised criteria for the classification of SLE. Arthritis Rheum. 25:12711277.

38. Burlingame, R.W., and R.L. Rubin. 1990. Subnucleosome structures as substrates in enzyme-linked immunosorbent assays. J. Immunol. Methods. 134: 187-199.

39. Tsao, B.P., K. Ohnishi, H. Cheroutre, B. Mitchell, M. Teitell, P. Mixter, M. Kronenberg, and B.H. Hahn. 1992. Failed self-tolerance and autoimmunity in IgG anti-DNA transgenic mice. J. Immunol. 149:359-358.

40. Morton, N.E., A. Collins, S. Lawrences, and D.C. Shields. 1992. Algorithms for a location database. Ann. Hum. Genet. 56:223-232.

41. Ott, J. 1991. Methods of linkage analysis: nonparametric approaches. In Analysis of Human Genetic Linkage. Revised edition. Johns Hopkins University Press, Baltimore. 77-80.

42. Tran, L.D., R.D. Elston, B.J.B. Keats, and A.F. Wilson. 1994. Statistical Analysis for Genetic Epidemiology, Release 2.2. Software Sib-Pair Linkage Program Version 2.6. System requirement: IBM Pentium.

43. S.A.G.E. 1994. Statistical analysis for genetic epidemiology, Release 2.2. System requirement: IBM Pentium. Computer program package available from the Department of Biometry and Genetics, LSU Medical Center, New Orleans.

44. Haseman, J.K., and R.C. Elston. 1972. The investigation of linkage between a quantitative trait and a marker locus. Behav. Genet. 2:3-19.

45. Blackwelder, W.D., and R.O. Elston. 1985. A comparison of sib-pair linkage tests for disease susceptibility loci. Genet. Epidemiol. 2:85-97.

46. Thomson, G. 1994. Identifying complex disease genes: progress and paradigms. Nature Genet. 8:108-110.

47. Risch, N. 1990. Linkage strategies for genetically complex traits. II. The power of affected relative pairs. Am. J. Hum. Genet. 46:229-241.

48. Wu, D.A., X. Bu, C.H. Warden, D.D.C. Shen, C.-Y. Jeng, W.H.H. Sheu, M.M.T. Fuh, T. Katsuya, V.J. Dzau, G.M. Reaven, et al. 1996. Quantitative trait locus mapping of human blood pressure to the lipoprotein lipase gene locus on chromosome 8p22. J. Clin. Invest. 97:2111-2118.

49. Green, J.R., and J.C. Woodrow. 1977. Sibling method for detecting HLA-linked genes in disease. Tissue Antigens. 9:31-35.

50. Cantor, R.M. 1989. A linkage test with identity-by-descent marker data from pairs of affected relatives. In Multipoint Mapping and Linkage Based Upon Affected Pedigree Members: Genetic Analysis Workshop 6. R.C. Elston, M.A. Spence, S.E. Hodge, and J.W. MacCluer, editors. Alan R. Liss Inc., New York. 111-116.

51. Risch, N. 1987. Assessing the role of HLA-linked and unlinked determinant of disease. Am. J. Hum. Genet. 49:1-14.

52. Copeman, J.B., F. Cucca, C.M. Hearne, R.J. Cornall, P.W. Reed, K.S. Ronningen, D.E. Undlien, L. Nistico, R. Buzzetti, R. Tosi, et al. 1995. Linkage disequilibrium mapping of a type 1 diabetes susceptibility gene (IDDM7) to chromosome 2q31-q33. Nature Genet. 9:80-85.

53. Cordell, H.J., and J.A. Todd. 1995. Multifactorial inheritance in type 1 diabetes. TIG 11:499-504.

54. Kuokkanen, S., M. Sundvall, J.D. Terwilliger, P.J. Tienari, J. Wiksstrom, R. Holmdahl, U. Petterson, and L. Peltonen. 1996. A putative vulnerability locus to multiple sclerosis maps to 5p14-p12 in a region syntenic to the murine locus Eae2. Nature Genet. 13:477-480.

55. Botto, M., E. Theodoridis, E.M. Thompson, H.L. Beynon, D. Briggs, D.A., Isenberg, M.J. Walport, and K.A. Davies. 1996. FcyRIIa polymorphism in systemic lupus erythematosus (SLE): no association with disease. Clin. Exp. Immunol. 104:264-268.

56. Kumar, A., A. Kumar, S. Sinha, P.S. Khadekar, K. Banerjee, and L.M. Srivastava. 1995. Hind III genomic polymorphism of the C3b receptor (CR1) in patients with SLE: low erythrocyte CR1 expression is an acquired phenomenon. Immunol. Cell Biol. 73:457-462.

57. Barton, D.E., B.E. Foellmer, J. Du, J. Tamm, R. Derynck, and U. Francke. 1988. Chromosomal mapping of genes for transforming growth factor beta-2 and beta-3 in man and mouse dispersion of TGF-beta gene family. Oncogene Res. 3:323-331.

58. Herzog, H., B.U. Zabel, R. Schneider, B. Auer, M. Hirsch-Kauffmann, and M. Schweiger. 1989. Human nuclear NAD(+) ADP-ribosyltransferase: localization of the gene on chromosome 1q41-q42 and expression of an active human enzyme in Escherichia coli. Proc. Natl. Acad. Sci. USA. 86:3514-3518.

59. Nishimura, D.Y., A.F. Purchio, and J.C. Murray. 1993. Linkage localization of TGFB2 and the human homeobox gene HLX1 to chromosome 1q. Genomics. 15:357-364.

60. DeMartin, R., B. Haendler, R. Hofer-Warbinek, H. Gaugitisch, M. Wrann, H. Schusener, J.M. Seifert, S. Bodmer, A. Fontana, and E. Hofer. 1987. Complementary DNA for human glioblastoma-derived $\mathrm{T}$ cell suppressor factor, a novel member of the transforming growth factor-beta gene family. EMBO J. 6:3673-3677.

61. Raz, E., J. Dudler, M. Lotz, S.M. Baird, C.C. Berry, R.A. Eisenberg, and D.A. Carson. 1995. Modulation of disease activity in murine systemic lupus erythematosus by cytokine gene delivery. Lupus. 4:286-292.

62. Deguchi, Y., D. Agus, and J.H. Kehrl. 1993. A human homeobox gene, HB24, inhibits development of CD4+ T cells and impairs thymic involution in transgenic mice. J. Biol. Chem. 268:3646-3653.

63. Loetscher, P., R. Alvarez-Gonzalez, and F.R. Althaus. 1987. Poly(ADPribose) may signal changing metabolic conditions to the chromatin of mammalian cells. Proc. Natl. Acad. Sci. USA. 84:1286-1289.

64. Haug, B.L., J.S. Lee, and J.T. Sibley. 1994. Altered poly(ADP-ribose) metabolism in family members of patients with systemic lupus erythematosus. J. Rheum. 21:851-856. 